\title{
Investigating the link between self directed learning readiness and project based learning outcomes: the case of international Masters Students in an engineering management course
}

\begin{abstract}
Modern learning approaches increasingly have fewer structured learning activities and more self directed learning tasks guided through consultation with academics. Such tasks are predominately project/problem based where the student is required to follow a freely guided road map to self discovery whilst simultaneously achieving desired learning outcomes for a particular course. However, many international students struggle to adjust to an Australian higher learning environment where they are being increasingly encouraged to undertake self directed learning (SDL). Thus, this paper proposes the concept that international students who have higher readiness for SDL gain greater learning outcomes from project based learning (PBL) approaches. To achieve this objective, a questionnaire survey of 26 students (65 per cent of class) completing an engineering management course was conducted. Linear regression analysis provided evidence that SDL readiness was a key enabler for achieving learning outcomes from PBL. In particular, having high self management skills was shown to be the most significant and reliable predictor for achieving learning outcomes from PBL. Through understanding students SDL readiness at the commencement of their engineering programs, academics can better tailor PBL support mechanisms to achieve desired learning outcomes.
\end{abstract}

Keywords: self directed learning, project based learning, engineering management, international students 


\section{Background}

Advances in technologies mean that students can now access a plethora of material through an Intranet or over the Internet to support their learning processes. However, the changing nature of the engineering industry requires constant changes to the educational process, and our reliance upon technology should not be the only driving mechanism for educational advancement (e.g. Coates 2000; Toft 2003). Modern engineering education programs should prepare students for scenarios which mimic those faced by engineering practitioners. Project-based learning (PBL) has helped, to some extent, students to cohesively conceptualise engineering fundamentals to develop holistically acceptable solutions for engineering problems (e.g. Lemckert 1999; Woods et al. 2000; Gibson 2003; Mills and Treagust 2003; Ribeiro and Mizukami 2005). However, international students commencing an Australian postgraduate program in engineering have often graduated from undergraduate programs where a teacher centred learning approach is still predominately practiced. Teacher centred learning has some advantages but may not provide students with the necessary skills to tackle PBL activities. Students with some previous exposure to PBL should demonstrate higher rates of self directed learning (SDL) readiness. The following sub-sections provide a brief background on international student learning in an engineering management context, SDL with a particular emphasis on Giglielminos' (1977) readiness scale and finally PBL. As this study focuses on the interrelationship between these three themes it was deemed imperative to include a brief background on each.

\subsection{International student learning in an engineering management context}

In recent years, the proportion of international students participating in the Australian higher education sector has increased exponentially. Moreover, this same trend is being experienced in the U.S., in Europe and in other developed nations, resulting in an opening awareness of the international dimension in higher education (Callan 2000). However, many international students face a number of head winds, preventing them from learning at similar rates as domestic students. Examples include, limited interaction with local students and industry professionals (Knight 1997), low English language proficiency (Barrett and Huba 1994; Lewthwaite 1996), cultural adjustment (Wan et al. 2005), avoiding plagiarism (Duff et al. 2006), to name a few. In particular, one of the fundamental difficulties facing many international students is that they 
also must adapt to unfamiliar teaching and learning styles that have evolved to meet the more individualistic and communicative behaviours of domestic students. In particular, research undertaken by Tompson and Tompson (1996) cite behavioural characteristics such as limited classroom participation, not asking for clarification, and studying only with international students as behaviours that undermine international students’ academic performance. Moreover, before international students can become confident self-learners they must make a significant behavioural adjustment by shifting from an instructional method of learning to a free learning environment in which they have to solve problems rather than memorising facts (Ladd and Ruby 1999). Specifically, students needed to be more independent in their approach instead of relying totally on academics. This is particularly true for project based work, where a student may be required to interact with peers and industry professionals to achieve desired outcomes. Many engineering programs at the undergraduate and postgraduate level are beginning to incorporate a greater degree of PBL activities to expose students to more practical engineering environments. The Griffith School of Engineering is no exception, where PBL is gradually being implemented across the entire spectrum of programs offered.

\subsection{Self directed learning readiness}

SDL is a continuous engagement in acquiring, applying and creating knowledge and skills in the context of an individual learner's unique problems. SDL capabilities are critical in the ever changing knowledge economy where the only constant is change. Instilling a lifelong learning perspective implies that schools and universities need to prepare learners to engage in SDL processes. However, general consensus is that K12 education is still largely teacher centred. Moreover, many University programs, including those in applied fields such as engineering, have only fractional components of activities which infuse SDL skills and these are usually in the final years of undergraduate programs. When students are finally thrust into such tasks in their engineering programs they are largely unprepared and sometimes struggle to sufficiently adapt. Once they start to develop a basic skill set for SDL in their final year, they are catapulted into the engineering profession, where they will undoubtedly be expected to adopt a SDL approach from day one. Earlier SDL preparation will ensure a smoother transition to professional employment in engineering and other professional areas. 
Two Likert-type instruments available for the assessment of readiness for SDL are Guglielminos' (1977) self-directed learning readiness scale (SDLRS) and Oddi’s (1986) continuing learning inventory (OCLI). SDLRS is a better instrument since it addresses both attributes and skills along with its more extensive literature foundations. Moreover, greater evidence of its construct, content and criterion reliability and validity are also prevalent in the literature (e.g. Delahaye and Smith 1995; Maltby et al. 2000). Thus, for the purpose of this paper the SDLRS was deemed as the most suitable instrument for soliciting an accurate measurement of readiness for SDL. The version of the instrument used in the study was a self-scoring form. The self-scoring SDLRS is composed of three factors, namely, self management, desire for learning and self control. Each of these factors is composed of a number of items for rating SDLRS (see Table 1). Later sections provide a detailed description on the use of the SDLRS instrument in the context of this study.

\subsection{PBL in engineering}

PBL has been defined as problem and/or project-based learning. Similarities are that both methods endeavour to mimic professional situations in either exploring a problem or a project with more than one way to either solve the problem or implement the project. For the purpose of this study, the term PBL was taken to mean project based learning, since all project based activities involve inter alia problem solving of one kind or another (Gibson 2003). PBL aims to move students beyond traditional surface learning approaches concerned primarily with the gathering and memorising of facts and other forms of information to one that is characterised by learners understanding material, seeking meaning, relating concepts to experience, critically evaluating ideas and so on (PBLE 2003). Birch (1986) argued that PBL was the most effective means of developing the general qualities of mind of the student, to securing an integration of academic and operational approaches to higher education and to instilling a high level of motivation and a capacity for active learning. In an engineering context, PBL is undoubtedly an effective means for teaching and assessing a range of relevant skills and qualities needed by the graduate engineer. PBLE (2003) summarises the benefits of PBL as: improved comprehension; improved context and student motivation; theory is learnt and applied in a situation resembling a work based scenario; improved communication skills for theory based content; ability to apply theory to a real application; and improved retention. 
Many Universities offering engineering programs across the globe are engaging with PBL as a preferred form of learning. Outstanding examples include Aalborg, Drexel, Windsor and Surrey. Closer to home, many Australian Universities are presently involved in multi-million dollar initiatives implementing PBL into their engineering programs. Engineers Australia (EA) views such steps to re-design curriculum around PBL as an opportunity to derive graduate competency requirements. Similarly to the experience in Australia, engineering institutions world wide are beginning to demand more stringent requirements from accredited engineering programs. Specifically, they want curriculum to be designed around graduate competencies and that the development of those competencies will dictate the type of delivery mode for course content; PBL being an obvious vehicle to achieve such competencies at both the undergraduate and postgraduate levels (Ribeiro and Mizukami, 2005).

\section{PBL in an engineering management postgraduate course}

Engineering at Griffith University, Australia, has recently merged from three different schools to one larger school, with a reconstructed postgraduate engineering program commencing delivery in 2008. This presents an excellent opportunity to explore the possibility of expanding PBL through Griffith's engineering curriculum, with the potential outcomes of improved student retention, increased motivation and improved graduate outcomes. This style of learning also has the added benefit that the University has a higher level of engagement with the industry through course design which is more likely to ensure currency of curriculum. Whilst some institutions have created entire engineering programs based on PBL, the Griffith School of Engineering seeks to implement PBL as a major component of a broad portfolio of learning and teaching options. Others include, research based learning, work integrated learning and traditional teacher centred learning approaches. This paper discusses the pilot implementation and evaluation of a PBL exercise in a course titled 7056ENG Resource Planning and Management which is a core course in both the existing and revised Master of Engineering Management program. Over ninety per cent of the students enrolled in this program are full fee paying postgraduate students. A full description of the background of the course cohort that responded to the questionnaire is provided in the next section. 
The course contact hours for this course totalled forty. This was made up of 18 hours of lectures, 10 hours of computer laboratories and 12 hours of tutorials. It should be noted that this courses contact hours are approximately one third lower than the majority of engineering courses offered at the Griffith School of Engineering. Apart from a final week revision lecture, the content delivery was completed by week eight of a thirteen week semester. This approach was adopted to provide students with course fundamentals earlier in the semester in order that they can spend greater time focused on SDL to complete their PBL task which carried a 100 per cent weighting. From week eight of the semester, assistance was provided through booked appointments with the course convenor. The students were required to complete one of two PBL tasks: (1) civil discipline project: resource planning and management for the design and construction of a luxury residence; and (2) multi-discipline engineering project: resource planning and management for the design, build and operation of a small steel reinforcement manufacturing facility. The background information and learning resources (e.g. plans, basic equipment specifications, etc.) for these two projects were sourced from Hyder consulting for the civil/construction project and Neumann Steel for the steel reinforcement project. Students were also provided with a list of requirements for their final report. As this course was related to resource planning, the students were requested to include such outcomes as work breakdown structures, estimates, Gantt charts, resource histograms, risk management plans, operation and maintenance plans, profitability analysis, etc. Students were required to submit individual reports but were encouraged to work together in the early stages of their project to discuss resource estimation and allocation issues.

\section{Research method}

As previously mentioned, the primary objective of this study was to confirm the hypothesis that international postgraduate students who have higher readiness for SDL gain more from PBL approaches. Literature analysis confirmed that SDLRS was the most appropriate instrument for determining SDL readiness. After selection of the instrument, the cross-sectional study was designed and executed accordingly. This study solicited the perceptions of a cohort of forty students who completed a course in resource planning and management. This course is core in the Master of Engineering Management program. As previously mentioned, the majority of the students completing this course are full fee paying international students that have completed an undergraduate engineering program from another nation. In total, 26 questionnaire 
surveys were completed by the class cohort representing a response rate of 65 per cent. The questionnaire survey contained five distinct sections. The first section solicited descriptive statistics on the participating respondents. This section enabled the establishment of a comprehensive respondent profile (i.e. age, industry, experience, undergraduate degree, etc.). The second section requested respondents to provide their opinion about statements related to the SDLRS, ranging from ' 1 = strongly disagree' to ' $5=$ strongly agree'. These SDLRS questions were categorised under three factors, namely, self management (13 items), desire for learning (12 items) and self control (15 items). The third section asked respondents to detail their past experience with PBL and provide an estimated break down of assessment items completed in their undergraduate studies. The fourth section asked students to rate their experience with the major project conducted in this course. The purpose of this section was to ascertain the students' confidence with undertaking an unfamiliar planning task before and after completing this course, examining how many productive hours they spent undertaking a range of tasks associated with the project and whether they believed that the activity improved their job readiness. Finally, the last section asked respondents to rate a number of questions relating to the extent to which they perceived that they achieved particular learning outcomes from the course, on a scale ranging from ' $1=$ not at all' to ' $5=$ great extent'.

Apart from descriptive analysis techniques, linear regression analysis was utilised to determine the relationship between construct and overall ratings for SDLRS and those for learning outcomes. A complete description of the analysis methodologies adopted is provided in the following section. The author concedes that the collected sample size may not be of an appropriate size to make statistically significant statements about SDL readiness and the extent of learning outcomes achieved from the PBL environment. However, the results provide sufficient evidence to persuade convenors to better design their postgraduate programs which attract high proportions of international students.

\section{Data analysis and results}

\subsection{Respondent profile}

Similarly to the undergraduate Bachelor of Engineering program offered at Griffith, which is largely composed of domestic students, only a fraction of the students were female (8\%). This provides some 
evidence that engineering and construction undergraduate programs globally also fail to attract significant numbers of female students. The majority of Masters Students are in their mid to late twenties (63\%) with only a small fraction $(\mathrm{N}=3)$ being over thirty years of age $(13 \%)$. As expected, the majority of the students were enrolled in the engineering/construction management programs (92\%). It is interesting to note, that eight per cent of the students were enrolled in the Master of Structural and Construction Engineering Program. This course is not a core course of this program, indicating the students interested in civil engineering design also have an interest in engineering management focused courses. The majority of the students enrolled in the course had an undergraduate degree in civil engineering (67\%). Expectedly, only one student (4\%) came from a non-engineering background, namely, architecture.

Griffith University engineering and construction management programs are largely filled by international full fee paying students. This course is no exception, with 92 per cent of students completing their undergraduate programs abroad. Only two students completed their undergraduate program in Australia (8\%). The majority of students enrolled were from India (38\%). Unexpectedly, no students that completed their undergraduate degree from China enrolled in the program. Language barriers may be the largest barrier to greater numbers of Chinese students entering the engineering/construction management programs in Australia. Surprisingly, a relatively large number of students $(\mathrm{N}=5 ; 21 \%)$ completed their undergraduate degrees in Iran. The remainder of the students completed their undergraduate programs from a variety of nations from Europe, South America and the Middle East region.

As expected for a Masters program, the majority of the students had some industry experience (92\%). Two of the students (8\%) posted 10+ years of experience. Of the students that had acquired industry experience, the majority were engaged in the civil engineering profession (civil engineer $=27 \%$; site engineer $=27 \%$; project manager $=14 \%$; structural engineer $=4 \%$ ). The remaining respondents had experience in mechanical engineering, architecture and electrical engineering. The students were also requested to estimate the makeup of assessment items in their undergraduate engineering programs. The averaged makeup was not dissimilar to that of domestic students undertaking a Griffith Engineering degree where 50 per cent of a course is typically exam based and the remaining 50 per cent fairly evenly spread between assignments, tutorial exercises, laboratories and projects. Similarly to local engineering programs, only a small fraction of 
assessment was devoted to project/problem based activities (12\%).

\subsection{Evaluating self directed learning readiness}

As previously mentioned, Giglielminos' (1977) SDLRS was utilised to evaluate each students SDL readiness. Table 1 details the range, mean and standard deviation for the thirty items comprising the three factors of the SDLRS, namely, self management (SM), desire for learning (DL) and self control (SC). Mean ratings for these items ranged from 3.29 (SM8) to 4.50 (DL1). Understandably, there are some large standard deviation scores indicating that the respondents had varied levels of SDL readiness. The respondents appeared to have a relatively high desire for learning $(\mathrm{DL}=4.14)$ which was promising. This value would be expectedly higher for postgraduate students since they have already completed an undergraduate program as well as work experience and now seek further knowledge in the field of engineering management. Self management was the lowest rating factor with a mean value of 3.73. This provides some hints that some students have difficulty managing their approach to learning.

For the self management factor, two items relating to the planning and time management of study (i.e. SM4 and SM8) were the lowest. The busy lives of modern students that mix large working commitments with study may make it difficult to plan out a regular study routine. The respondents appeared to have a strong desire for learning indicated by the high mean values for a substantial number of the associated sub factors. DL12 had the lowest mean value in this factor (DL12 = 3.50) with a large standard deviation of 1.022 hinting that a number of students did not seek assistance when confronted with a daunting problem. Having an enjoyment for learning (DL5) also had highly varied responses indicating that the students' motives for study are varied. Lastly, the majority of the respondents appeared to have the necessary self control for study. Three items in this factor which fit under the theme of self appraisal and goal setting (i.e. SC10, SC12 and SC15) had high standard deviations. This may not be surprising since not all people are naturally strategic in their approach to learning. It should be noted that the SDLRS for individual respondents was utilised in a later section to establish a link between SDL readiness and learning outcomes from the PBL experience.

(INSERT TABLE 1) 


\subsection{Evaluating the PBL experience}

The respondents were requested to answer a number of questions related to their experience with their recently completed PBL activity and associated course as a whole. As mentioned above, the students had the opportunity to undertake a civil discipline or multi-discipline engineering project. Only four students (25\%) attempted the multi-disciplined steel manufacturing facility project with the remainder completing the luxury house project. The choice of project was understandable considering the undergraduate training profile of the students (i.e. predominately civil engineering). In order to ascertain whether the students had gained some abilities as a resource planner from the PBL exercise and course they were asked how difficult they found it to get started for this project and also if they were required to plan another project again in their future employment how difficult they would find it (Figure 1a). Only four people (17\%) stated that the project was not difficult/slightly difficult. However, 54 per cent stated that if they had to plan a project again, they would find it not difficult/slightly difficult. Similarly, they were asked how confident they would be to tackle a large project planning exercise pre- and post- course completion (Figure 1b). Only 50 per cent of the respondents were somewhat confident to extremely confident (3-5) to complete a large project prior to commencing this course. This increased to 87 per cent after completing the course. Together, both of these questions provide solid evidence that the course, particularly the adopted PBL approach has enhanced their capability to tackle large 'real world' resource planning problems.

\section{(INSERT FIGURE 1)}

The students were asked whether they preferred an examination based on the course content than a 100 per cent PBL exercise that incorporates a large portion of the course content. The majority of the students preferred the PBL approach (75\%). However, 25 per cent of respondents preferred a final examination. This is unusual since students almost always prefer assignment based assessment. Unfamiliarity with such a PBL approach where the requirements, processes and outcomes are not fixed may be feared by some engineering students who prefer structured approaches to achieving solutions. Whilst, 25 per cent of respondents preferred a traditional assessment approach, almost all (92\%) have admitted that this approach has helped their job readiness. From my experience, if such a question was solicited from all students and averaged for 
all engineering courses offered within the School, such a high percentage would not be evident.

The per cent makeup of the total productive hours spent on the PBL activity was determined: (1) 0-20 hours $=4 \%$; (2) 21-40 hours = 4\%; (3) 41-60 hours = 21\%; (4) 61-100 = 29\%; (5) 101-150 = 29\%; and (6) $150+=$ 13\%. The median time spent on this project was 61-100 hours (i.e. 80 hours) which reflects the course convenors expectation of time allocated (100\% course assessment item). Course contact was a total of 40 hours for the course. Griffith University ten credit point courses consider that students should spend a total of 130 hours on a course i.e. 10 hours per week over a 13 week semester. Based on the median time spent by students, the total devoted time to this course was 120 hours (i.e. $40+80$ ). Some students may have spent additional time reading other course materials provided. This demonstrates that whilst this course had only one assessment item and relatively low contact hours (approx. 3 hours per week), the students were still devoting appropriate time to it (i.e. 10 hours per week). The project has taken the focus away from teacher directed learning where course contact hours make up two thirds of total time spent to SDL where the ratio has been reduced to one third. The students appeared happy with this shift to a SDL approach with 79 per cent indicating that they were not expected to spend too much time on this project.

Not only were the students requested to detail the total time spent on the PBL project but also the various learning (L) and task ( $\mathrm{T}$ ) based activities which are contained within it (see Table 2). These averaged percentage breakdowns were also translated to hours-spent allocations using the median time spent on the activity by the students (i.e. 80 hours). Table 2 demonstrates that students devoted 38 per cent of their time to research-based learning prior to commencing the actual task based activities which contribute to the project outcomes. Based on a 38 per cent allocation and the median time spent on this project (i.e. $0.38 \times 80=30.4$ hours) a total of 30 hours or approximately two hours per week was spent on self directed research based learning. This course was designed to ensure that core content was taught in the first 6 weeks of the 13 week semester. The students were then coaxed into SDL to gain the necessary skills to complete their assignments. This two hours per week of SDL was supplemented by tutorial classes and computer labs introducing different planning software packages. As previously mentioned, this course purposely had a low course contact profile compared to traditional engineering courses to allow for extra time spent out of contact hours. The majority of self-directed learning was spent acquiring new knowledge (L1 = 16\%; 13 hours) and skills 
(L2 = 12\%; 10 hours). It was pleasing to see that students spent five per cent of their time (i.e. 4 hours) consulting industry professionals to overcome certain hurdles. With regards to the task based activities, the students expectedly spent the most of their time on formulating estimates and the precedence diagram for the project $(\mathrm{T} 1=18 \% ; 14$ hours). The second highest task based activity was building and analysing the plan in their chosen software package ( $\mathrm{T} 2=16 \% ; 13$ hours).

\section{(INSERT TABLE 2)}

Finally, the students were requested to rate the extent to which they gained capabilities or skills in the courses fourteen 'generic skills' and 'topic specific' learning outcomes (Table 3). Learning outcome mean evaluations ranged from 3.26 for LO5 to 4.17 for LO10 with an overall mean of 3.83, highlighting that on average, the students achieved learning outcomes to a fairly large extent. Standard deviations ranged from 0.596 to 0.905 , indicating that whilst all students gained at least moderate skills from the PBL exercise some gained significantly more. Sadly, the students only gained moderate skills to communicate with peers and industry $(\mathrm{LO} 5=3.26)$. It was envisaged that the students would engage more with peers and in particular industry practitioners. However, due to the current busy climate in the Australian engineering and construction industry, the students would have found it difficult to consult industry professionals. At the other end of the scale, it was always hoped for, but still surprising that the students highest rated learning outcome was that they gained to a large extent the ability to be an independent learner ( $\mathrm{LO} 10=4.17)$. In the authors humble opinion, regardless of the program completed, a University education should develop individuals with the ability to learn independently, construct information holistically and critique such information wisely. Learning outcome evaluations for individual respondents were utilised in the next section in order to investigate whether SDL readiness is a key predictor of learning outcomes.

(INSERT TABLE 3)

\subsection{Linking SDLRS with PBL outcomes}

The primary objective of this paper was to determine whether SDL readiness was a key predictor on the extent to which the cohort of postgraduate students gained learning outcomes from the assigned PBL activity 
and course. To achieve this objective, the mean values for the 26 individual respondents for the three factors of the SDLRS, as well as the overall SDLRS values were plotted against the overall mean learning outcome values. Linear regression analysis was then utilised to extract any significant relationships and ultimately uncover any evidence that those students that rated highly on the SDLRS gained more from this PBL structured course. Figure 3 illustrates the developed scatter plots for each SDLRS factor (i.e. SM: a; DL: b; and SC: c) and the overall SDLRS (i.e. SDLRS: d) versus overall learning outcome ratings. This exercise provided evidence that self management (SM) was the best predictor for achieving learning outcomes from PBL. The unstandardised linear equation for SM has the highest coefficient of the three factors (i.e. 0.72). Additionally, this equation had the highest $R^{2}$ value of 0.50 and was significant at the 0.01 level. This result suggests that students which have higher self management of their learning will gain more from PBL environments. This is not surprising since PBL requires students to explore, gather knowledge and make decisions in a timely manner. Nonetheless, this result affirms the idea that students which are pro-active and systematic in their approach to learning will gather data early and be able to make more informed decisions throughout different stages of their project, ultimately leading to more complete outcomes. Whilst such outcomes are important to achieving project aims, the students more importantly gain a higher sense of fulfilment because they have explored the problem in a deeper manner and gained more skills on the way.

The remaining two SDLRS factors (i.e. DL and SC) displayed a positive linear relationship with reasonable coefficient values. However, their $R^{2}$ values were low. This hints that whilst such factors may be key enablers of higher learning outcomes they are not necessarily as reliable as SM. The lower reliability of these two factors may be due to a number of reasons. Firstly, the study was drawn from a relatively small sample size. Secondly, some students who may have had a strong DL may not have gained as much from PBL since they were too unfamiliar with the approach. Thirdly, items contained within the SC factor appear mainly targeted at highly individualistic approaches to life and learning which may be considered more important PBL learning indicators in a Western learning context. However, a large proportion of the respondents contained in this sample were educated in a central Asian context where such attributes may not be encouraged as strongly. Regardless, all three scatter plots show a positive inclined trend between SDL readiness factors and learning outcomes. Moreover, the combined SDLRS linear regression curve (Figure 
2d) provides evidence that Giglielminos' scale could potentially be used to ascertain whether a student will perform satisfactorily in PBL environments.

(INSERT FIGURE 2)

\section{Conclusion}

Griffith Engineering School, along with many other higher education providers globally, are slowly incorporating PBL into their undergraduate and postgraduate programs. However, the transition to PBL is not an easy one due to a number of internal and external environment barriers. Firstly, internally within existing engineering Schools, the academic staff may be reluctant to embrace PBL and those which are accepting may not have the imagination and knowledge to make it work. Also, entire engineering programs and the courses contained within need to be totally restructured to ensure that PBL is not applied ad-hoc but seamlessly imbedded. Such an undertaking requires motivated staff and a serious investment in strategic resources. Secondly, the external barriers, including, secondary education systems still predominately adopting teacher centred learning approaches, higher working commitments of students, to name a few, all make PBL difficult to effectively implement. These internal and external barriers have contributed to the creation of students with a limited SDL readiness. SDL aptitude is one key outcome from PBL and appropriate SDL readiness is also a precursor for extracting higher levels of learning from PBL environments. Graduating students with heightened SDL aptitude is one of the best outcomes an engineering education provider can offer the professional employment market. Thus, as hinted in this paper, the measurement of SDL readiness at various stages of a students enrolment in an engineering program may be an essential process to ensure learning outcomes are achieved, especially where PBL is employed. More importantly, such measurements may help convenors to construct programs which gradually develop SDL skill levels to suit assigned PBL tasks (i.e. as SDL readiness develops so does the difficultly of PBL tasks). Additionally, such measurements could even be used to identify and assist students at risk in PBL environments, particularly in the case of international students. These students were educated in different systems with highly variable approaches and standards, thus some require special attention when thrust into

PBL environments. Regardless of a student's educational background, the structured and continual 
evaluation of SDL readiness and the learning outcomes achieved from PBL environments will undoubtedly lead to engineering graduates which are highly employable in a range of industry sectors.

\section{References}

Barrett, M.F. and Huba, M.E., Factors related to international undergraduate student adjustment in an American community. College Student Journal, 1994, 28, 422-436.

Birch, W., Towards a model for problem-based learning. Studies in Higher Education, 1986, 11, 73-82.

Callan, H., The international vision in practice: a decade of evolution. Higher Education in Europe, 2000, 25, $15-23$.

Coates, J.F., Innovation in the future of engineering design. Technological Forecasting and Social Change, 2000, 64, 121-132.

Delahaye, B.L. and Smith, H.E., The validity of the learning preference assessment. Adult Education Quarterly, 1995, 45, 159-173.

Duff, A.H., Rogers, D.P. and Harris, M.B., International engineering students - avoiding plagiarism through understanding the Western academic context of scholarship, European Journal of Engineering Education, 2006, 31, 673-681.

Gibson, I.S., From solo-run to mainstream thinking: project-based learning in engineering design. European Journal of Engineering Education, 2003, 28, 331-337.

Guglielmino, L., Development of Self-Directed Learning Readiness Scale. Doctoral Dissertation, University of Georgia, 1977. 
Knight, J., Internationalisation of higher education: a conceptual framework. In J. Knight and H. de Wit (Eds.), Internationalisation of Higher Education in Asia-Pacific Countries, European Association for International Education, 1997.

Ladd, P.D. and Ruby, R., Learning style and adjustment issues for international students. Journal of Education for Business, 1999, 74, 363-367.

Lemckert, C.J., Improving the delivery of problem/project-based learning in a traditional teaching ernvironment. $2^{\text {nd }}$ Asia-Pacific Forum on Engineering \& Technology Education, UICEE Sydney, Australia, 4 - 7 July 1999.

Lewthwaite, M., A study of International students' perceptions of cross-cultural adaptions. International Journal for the Advancement of Counselling, 1996, 19, 167-185.

Maltby, J., Lewis, C., and Hill, A., Commissioned Reviews of 250 Psychological Tests. Wales, U.K.: Edwin Mellen Press, 2000.

Mills, J.E. and Treagust, D.F., Engineering education - is problem-based or project-based learning the answer? Australasian Journal of Engineering Education, 2003, 11, 2-16.

Oddi, L.F., Development and validation of an instrument to identify self-directed continuing learners. Adult Education Quarterly, 1986, 36, 97-107.

PBLE, A Guide to Learning Engineering through Projects. Fund for the Development of Teaching and Learning. Project Based Learning in Engineering, www.pble.ac.uk, 2003.

Ribeiro, L.R.C. and Mizukami, M.G.N., Problem-based learning: a student evaluation of an implementation in postgraduate engineering education. European Journal of Engineering Education, 2005, 30, 137-149. 
Toft, Y., Howard, P. and Jorgensen, D., Human-centred engineers - a model for holistic interdisciplinary communication and professional practice. International Journal of Industrial Ergonomics, 2003, 31, 195202.

Tompson, H.B. and Tompson, G.H., Confronting diversity issues in the classroom with strategies to improve satisfaction and retention of international students. Journal of Education for Business, 1996, 72, 53-57.

Wan, T-Y., Chapman, D.W. and Biggs, D.A., Academic stress of international students attending U.S. Universities. Research in Higher Education, 2000, 33, 607-623.

Woods, D.R., Felder, R.M., Rugarcia, A. and Stice, J.E., The future of engineering education III developing of critical skills. Chemical Engineering Education, 2000, 34, 108-117. 
Table 1. SDLRS items range, mean and standard deviation

\begin{tabular}{|c|c|c|c|c|c|}
\hline $\begin{array}{l}\text { Item } \\
\text { code }\end{array}$ & $\begin{array}{l}\text { Factor } \\
\text { Sub factor (item) }\end{array}$ & Min. & Max. & Mean & $\begin{array}{l}\text { Std. } \\
\text { Dev. }\end{array}$ \\
\hline$S M$ & Self Management & 1 & 5 & 3.73 & 0.791 \\
\hline SM1 & I manage my time well & 1 & 5 & 3.71 & 1.042 \\
\hline SM2 & I am self disciplined & 2 & 5 & 3.88 & 0.900 \\
\hline SM3 & I am organised & 2 & 5 & 3.79 & 0.779 \\
\hline SM4 & I set strict time frames & 2 & 5 & 3.39 & 0.783 \\
\hline SM5 & I have good management skills & 2 & 5 & 3.75 & 0.897 \\
\hline SM6 & I am methodical & 2 & 5 & 3.67 & 0.702 \\
\hline SM7 & I am systematic in my learning & 2 & 5 & 3.54 & 0.721 \\
\hline SM8 & I set specific times for my study & 2 & 5 & 3.29 & 0.999 \\
\hline SM9 & I solve problems using a plan & 3 & 5 & 3.83 & 0.761 \\
\hline SM10 & I prioritise my work & 3 & 5 & 4.09 & 0.596 \\
\hline SM11 & I can be trusted to pursue my own learning & 3 & 5 & 3.92 & 0.717 \\
\hline SM12 & I prefer to plan my own learning & 2 & 5 & 3.67 & 0.761 \\
\hline SM13 & I am confident in my ability to search out information & 3 & 5 & 3.96 & 0.624 \\
\hline$\overline{D L}$ & Desire for learning & 1 & 5 & 4.14 & 0.785 \\
\hline DL1 & I want to learn new information & 4 & 5 & 4.50 & 0.511 \\
\hline DL2 & I enjoy learning new information & 3 & 5 & 4.38 & 0.647 \\
\hline DL3 & I have a need to learn & 3 & 5 & 4.17 & 0.963 \\
\hline DL4 & I enjoy a challenge & 3 & 5 & 4.38 & 0.711 \\
\hline DL5 & I enjoy studying & 2 & 5 & 3.78 & 0.902 \\
\hline DL6 & I critically evaluate new ideas & 2 & 5 & 3.83 & 0.816 \\
\hline DL7 & I like to gather facts before I make a decision & 2 & 5 & 4.21 & 0.779 \\
\hline DL8 & I like to evaluate what I do & 2 & 5 & 4.04 & 0.859 \\
\hline DL9 & I am open to new ideas & 3 & 5 & 4.13 & 0.741 \\
\hline DL10 & I learn from my mistakes & 3 & 5 & 4.29 & 0.751 \\
\hline DL11 & I need to know why & 3 & 5 & 4.42 & 0.717 \\
\hline DL12 & $\begin{array}{l}\text { When presented with a problem I cannot resolve I will ask for } \\
\text { assistance }\end{array}$ & 1 & 5 & 3.50 & 1.022 \\
\hline$S C$ & Self control & 1 & 5 & 4.05 & 0.756 \\
\hline SC1 & I prefer to set my own goals & 3 & 5 & 4.04 & 0.550 \\
\hline SC2 & I like to make decisions for myself & 3 & 5 & 4.38 & 0.576 \\
\hline SC3 & I am responsible for my own decisions/actions & 4 & 5 & 4.33 & 0.482 \\
\hline SC4 & I am in control of my life & 3 & 5 & 3.96 & 0.825 \\
\hline SC5 & I have high personal standards & 3 & 5 & 4.18 & 0.853 \\
\hline SC6 & I prefer to set my own learning goals & 3 & 5 & 3.88 & 0.797 \\
\hline SC7 & I evaluate my own performance & 2 & 5 & 3.79 & 0.833 \\
\hline SC8 & I am logical & 3 & 5 & 4.26 & 0.619 \\
\hline SC9 & I am responsible & 3 & 5 & 4.46 & 0.658 \\
\hline SC10 & I have high personal expectations & 2 & 5 & 3.96 & 1.042 \\
\hline SC11 & I am able to focus on a problem & 3 & 5 & 4.08 & 0.776 \\
\hline SC12 & I am aware of my limitations & 1 & 5 & 3.83 & 1.007 \\
\hline SC13 & I can find out information for my self & 3 & 5 & 3.88 & 0.612 \\
\hline SC14 & I have high beliefs in my abilities & 2 & 5 & 3.96 & 0.806 \\
\hline SC15 & I prefer to set my own criteria on which to evaluate my performance & 1 & 5 & 3.71 & 0.908 \\
\hline
\end{tabular}


Table 2. Break down of time spent on core project activities

\begin{tabular}{|c|c|c|c|}
\hline $\begin{array}{l}\text { Item } \\
\text { code }\end{array}$ & Activity description (L: Learning; T: Task) & Per cent & Hours* \\
\hline L1 & $\begin{array}{l}\text { Self directed research to learn new knowledge (i.e. to understand project, find } \\
\text { resources, etc.) }\end{array}$ & 16 & 13 \\
\hline L2 & Self directed research to learn new skills, techniques and software & 12 & 10 \\
\hline L3 & Consulting peers (e.g. asking class mates questions on unit rates, etc.) & 5 & 4 \\
\hline \multirow[t]{2}{*}{ L4 } & $\begin{array}{l}\text { Consulting industry (e.g. asking practitioners questions on unit rates, } \\
\text { sequencing, etc.) }\end{array}$ & 5 & 4 \\
\hline & Total for self directed learning activities & 38 & 31 \\
\hline T1 & Formulating the WBS, PDM and resource/duration estimates & 18 & 14 \\
\hline $\mathrm{T} 2$ & Building and analysing the chart in MS Project/Microplanner/Primavera & 16 & 13 \\
\hline T3 & Other sections (e.g. profitability analysis, crashing, etc.) & 11 & 9 \\
\hline \multirow[t]{2}{*}{ T4 } & Writing the professional report (i.e. presentation, discussion and format) & 14 & 11 \\
\hline & Total for task based activities & 59 & 47 \\
\hline \multirow[t]{2}{*}{$\mathrm{O} 1$} & Other & 3 & 2 \\
\hline & Total & 100 & 80 \\
\hline
\end{tabular}

*Based on median time spent on the project (i.e. L1 $=0.16 \times 80=13$ )

Table 3. Evaluating course learning outcomes

\begin{tabular}{llrrrr}
\hline $\begin{array}{l}\text { Item } \\
\text { code }\end{array}$ & Item description & Min. & Max. & Mean & $\begin{array}{r}\text { Std. } \\
\text { Dev. }\end{array}$ \\
\hline LO1 & Developed problem solving skills & 3 & 5 & 3.65 & 0.647 \\
LO2 & Gained knowledge of resource planning skills & 2 & 5 & 4.00 & 0.798 \\
LO3 & Developed the ability to think strategically & 3 & 5 & 4.09 & 0.668 \\
LO4 & Learned how and where to find relevant knowledge & 2 & 5 & 3.68 & 0.780 \\
LO5 & Improved ability to communicate with peers and industry & 2 & 5 & 3.26 & 0.689 \\
LO6 & Learned how to utilise planning software & 3 & 5 & 3.87 & 0.694 \\
LO7 & Learned how to apply theoretical knowledge & 3 & 5 & 3.74 & 0.689 \\
LO8 & Developed skills in recognising what knowledge is relevant for & 2 & 5 & 3.65 & 0.647 \\
& completing the project & & & & \\
LO9 & Developed skills in using technology for basic professional & 2 & 5 & 4.00 & 0.905 \\
& practice activities (e.g. word processing, internet, spreadsheets) & & & & \\
LO10 & Gained ability to be an independent learner & 2 & 5 & 4.17 & 0.778 \\
LO11 & Increased confidence to manage projects & 3 & 5 & 3.91 & 0.596 \\
LO12 & Improved time management skills & 2 & 5 & 3.82 & 0.853 \\
LO13 & Improved ability to solve problems with limited information & 2 & 5 & 3.77 & 0.813 \\
& and guidance & & & & \\
LO14 & Gained a 'deeper' understanding of the resource planning & 3 & 5 & 4.00 & 0.739 \\
& process & & & & \\
\hline
\end{tabular}




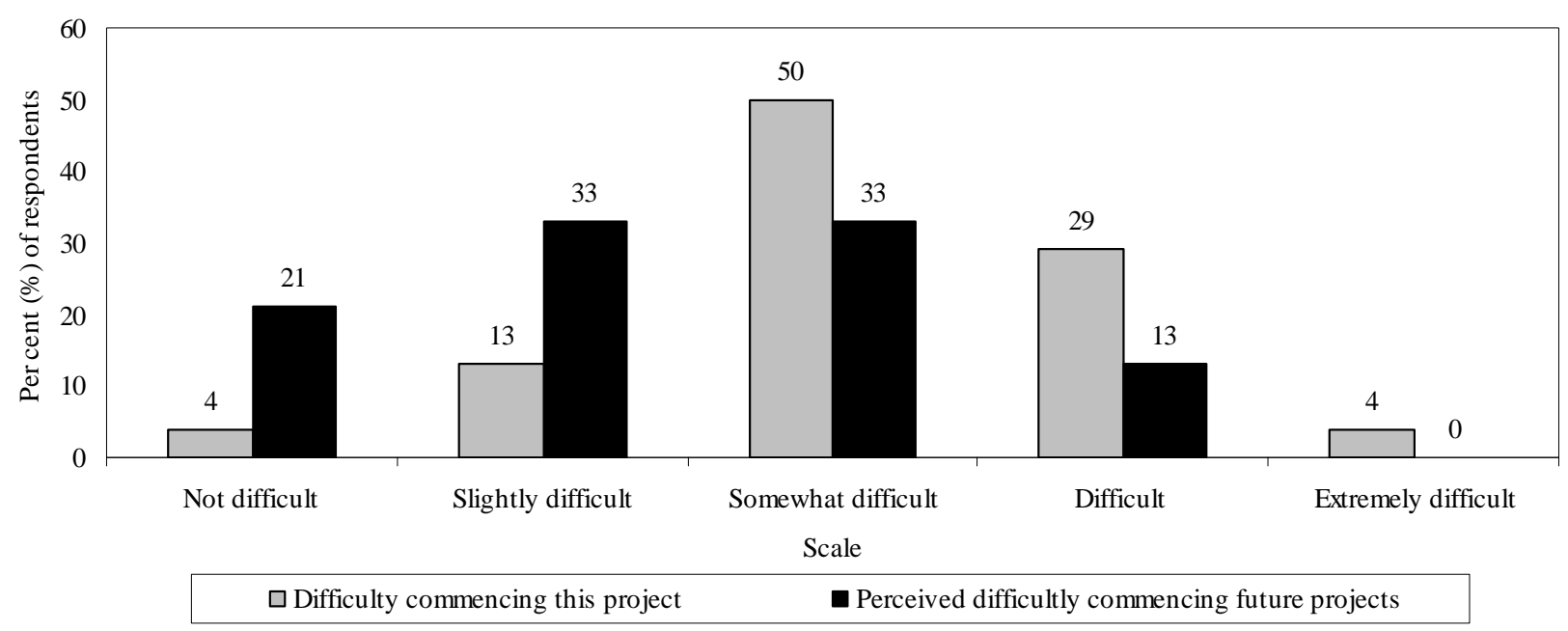

(a) Perceived difficulty planning this engineering project and future comparable projects

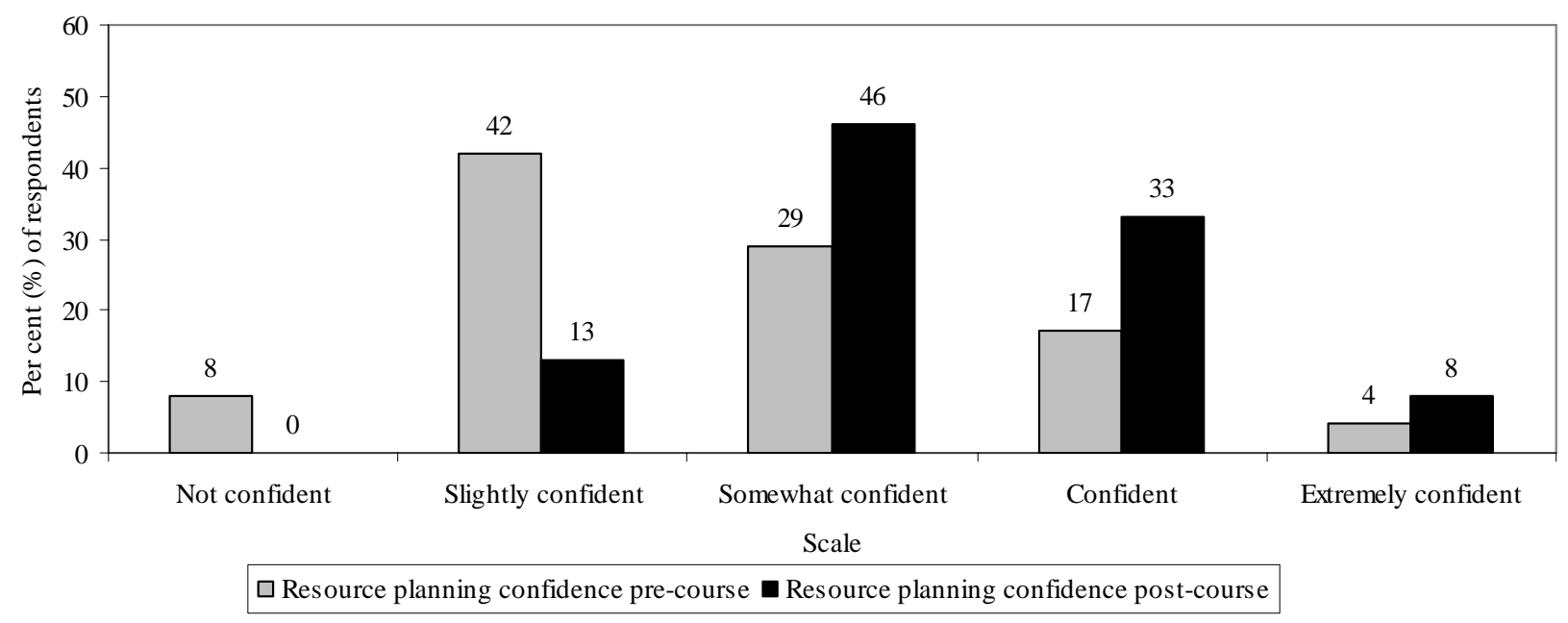

(b) Perceived confidence planning large engineering projects pre- and post- course completion

Figure 1. Perceived resource planning capability pre- and post- course completion 


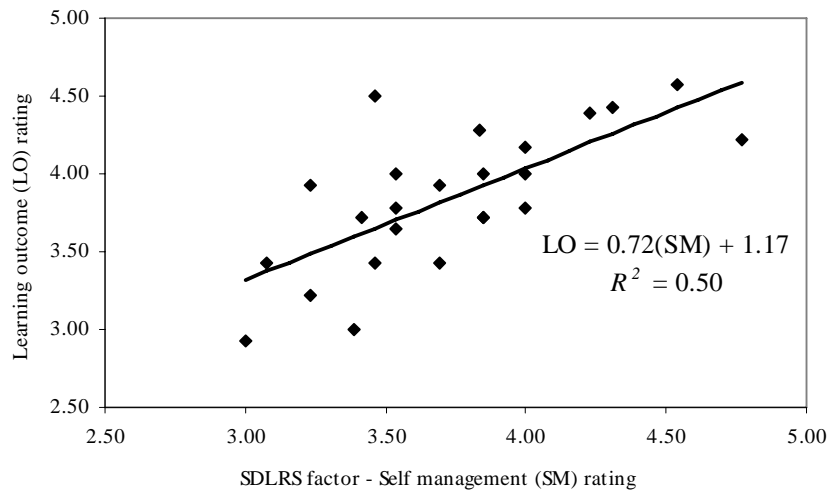

- Learning objectives — Linear (Learning objectives)

(a) Self management Vs Learning outcomes

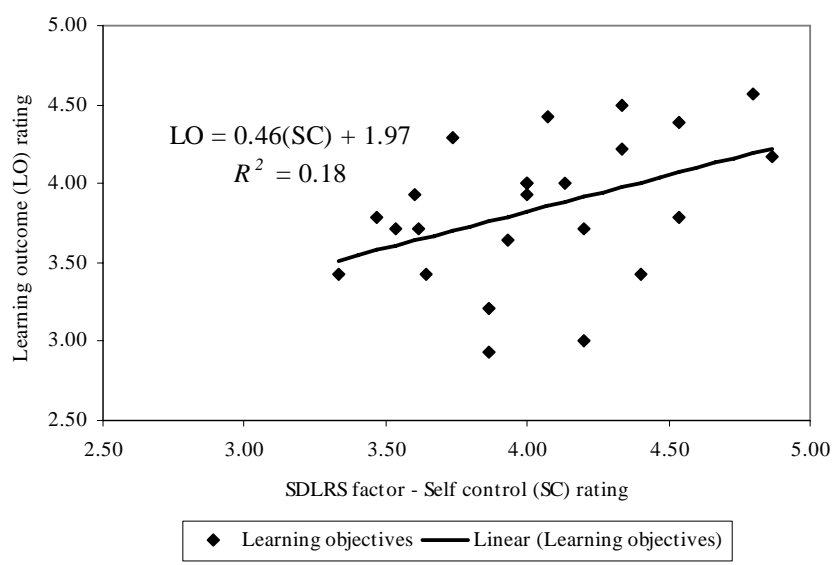

(c) Self control Vs Learning outcomes

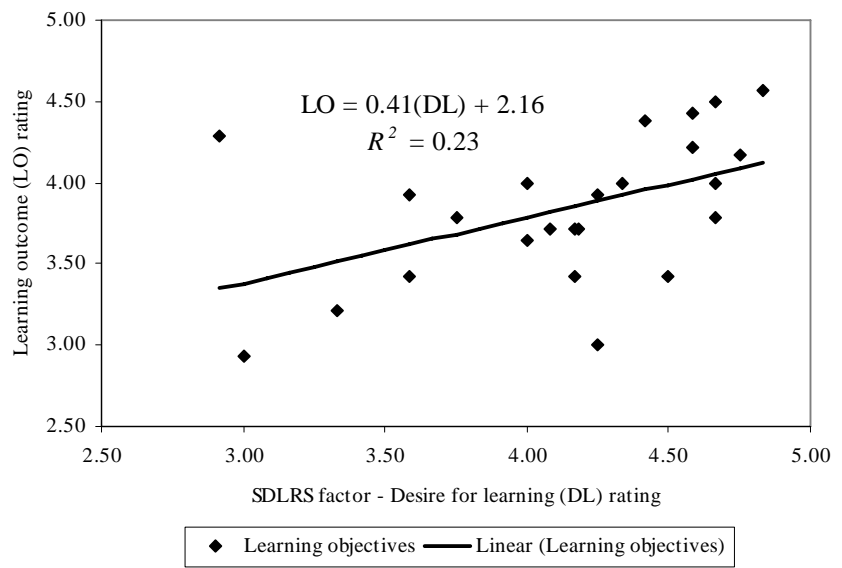

(b) Desire for learning Vs Learning outcomes

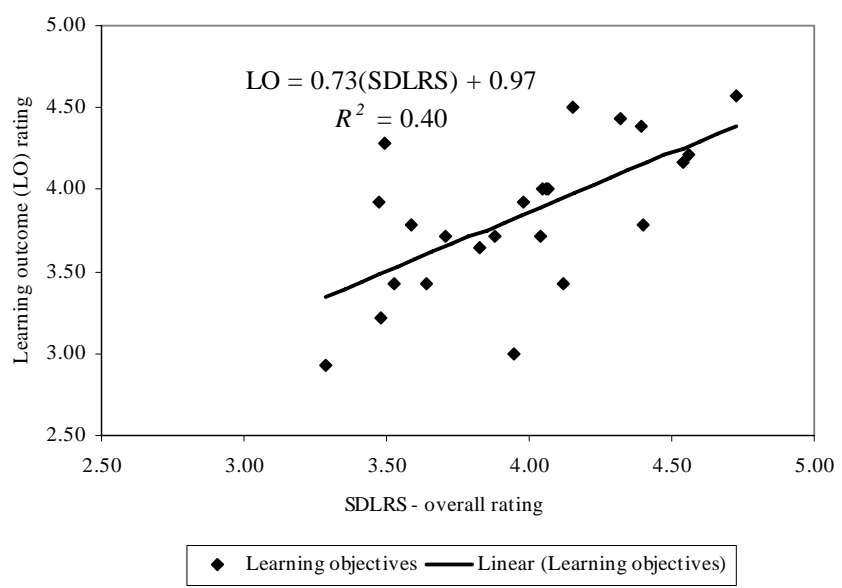

(d) SDLRS Vs Learning outcomes

Figure 2. Scatter plots of SDLRS factor and overall ratings versus learning outcome ratings 